\title{
Reflections on the Experiences of Turbaned Sikh Men in the Aftermath of $9 / 11$
}

\author{
Kiran S. K. Arora \\ University of Massachusetts Boston
}

\begin{abstract}
The murder of Trayvon Martin is a painful reminder of the violence perpetuated towards subjugated groups who are often deemed suspicious because of the color of their skin and/or clothing. The association of the hoodie and Black skin with being a member of a violent group is an association that is familiar for Sikh men. Many today are unaware of how Sikh men have been vilified because of their skin color and turbans. The terrorist attacks, which occurred on September 11, 2001, had a significant impact on turbaned Sikh men living in North America. These men have been targeted since then because of their shared visual image with the perpetrators of 9/11. This brief reflection discusses the experiences of discrimination these men have experienced, gives examples of psychological and relational injuries related to 9/11, and offers personal and professional lessons learned through conversations with turbaned Sikh men on their experiences.
\end{abstract}

Keywords: Sikhs, psychotherapy, turban, 9/11, counseling

\section{Voices}

Far too many of us suffer from the trauma and loss that originates from violence. Many people of color in the United States and Canada feel a personal connection to the murder and silencing of Trayvon Martin. His death is a reminder that the lives and deaths of subjugated people are often defined by those who hold power. Emotions in members of the Sikh community have been stirred by the killing of Trayvon Martin. Sikhs are acutely aware of the violence perpetuated towards those who look "different." Balbir Singh Sodhi, a turbaned Sikh and gas 
station owner in Mesa, Arizona, was murdered days after 9/11 in retaliation for the terrorist attacks. Prior to 9/11 turbaned Sikh men experienced racism because of their turbans, however after 9/11 racist attacks dramatically increased against them (Gohil \& Sidhu, 2008). While there are differences between the murder of Trayvon Martin and Sikh men who have suffered, I am reminded that marginalized people are burdened with the everyday realities of hate crimes. Unfortunately, we still live in a world where Black men and Sikh men are deemed violent, thugs, and terrorists because of their skin color and the hoodie or turban on their heads. The trauma Sikhs have experienced both historically and in contemporary times due to their turbans is profound and oftentimes goes unnoticed.

In this reflection, I wish to discuss the terrorist attacks of September 11, 2001 (hereafter referred to as 9/11), and how it has touched the lives of Sikhs. In particular, I will draw attention to the discrimination and its impact faced by many turbaned Sikh men in the backlash of $9 / 11$, and the lessons I have learned from listening to their stories. I want to be transparent by locating myself as a psychotherapist, researcher, and educator who belongs to the Sikh diaspora. My scholarship includes the exploration of historical and social trauma in Sikh families. As a member of the Sikh faith who also belongs to the broader mental health community, I have made it a life long commitment to create space for the voices of Sikh families in the field. Within the shadows of my work, I carry my own trauma stories both historical and contemporary. I am a daughter and sister of turbaned Sikh men and have been witness to their pain due to racial profiling in the aftermath of $9 / 11$. While the scope of this reflection is limited to the voices ${ }^{1}$ of the Sikh men I have had the privilege to work with as a psychotherapist and researcher, these voices have provided powerful testimony to the assaults inflicted on Sikhs as a consequence of 9/11 (Arora, 2009)

\section{The Sikh Turban in the Aftermath of 9/11}

In Sikhism, the practice of allowing one's hair to grow long is a symbol of respect towards God. The turban carries particular significance for Sikhs. It is an article of faith that represents piety, honor, and courage. The turban signifies the wearers' commitment to assisting those in need, as he is easily identifiable. A Sikh may wear his turban for any combination of these reasons or simply for his adherence to his faith (Gohil \& Sidhu, 2008). It is important to note that some Sikh women also wear turbans and warrant similar considerations.

After 9/11, Sikhs who shared Osama Bin Laden's visual image of the turban and beard came to be seen as suspicious and were targets of racial violence (Ahluwalia \& Pellettiere, 2010). The rage against those who committed the horrific crimes of 9/11 became directed at Sikhs and others who resembled the perpetrators. Hate crimes directed at Sikhs included murder, the burning of Gurudwaras (sacred places of worship), threats, bullying, and loss of jobs (United Sikhs, n.d.). In my conversations with Sikh men, they have shared incidents of being denied employment, refused service in restaurants, and refused the right to rent apartments all because of their turban. Other Sikh men have shared stories of being beaten, questioned on their views of $9 / 11$ in medical school interviews, hearing racial slurs, being targeted for

\footnotetext{
${ }^{1}$ The Sikh men whose voices I have included in this reflection have been given pseudonyms to protect their identity.
} 
excessive airport screenings, and being followed in stores by management. Simrat Singh ${ }^{2}$, a 22year old man born in the United States, told me he felt like an "outsider" in his country and although he was proud of his turban it easily singled him out.

While many men continue to wear their turban in the face of discrimination, for others these incidents have posed a spiritual challenge. The commitment to keeping one's hair long has been compounded with whether it is "safe enough" to live as a visible Sikh. I have heard Sikh men describe this internal dilemma as "being a possible sellout," and "maybe I'm not as strong a Sikh as I thought I was." The stress of living in a post-9/11 world is requiring some to rearrange the relationship they have with their faith.

\section{Examples of Psychological and Relational Injuries}

Discrimination often attempts to break the spirit of those who are marginalized. While I have witnessed extreme resiliency in the Sikh men I have worked with, I have also observed the psychological and relational cracks that the weight of discrimination has caused. Angad Singh, now a 29-year old man, shared his experience of been kicked and beaten on his way home from the train station in 2003. Before fleeing, his perpetrators called him "Rag head," "Osama's cousin," and told him to "get the fuck out of America." Angad Singh further shared that this hate crime has left him feeling afraid for his life, on edge, and anxious not knowing when the next attack will come. Angad Singh's case is one of many.

Kabir Singh was 40-years old and had only been in the United States for one month when 9/11 occurred. He worked as a taxi driver in upstate New York. At the time of the attacks the hood of his taxi and the front door to his apartment were spray painted with the words "brown towel head" and "go home Paki" [slur for Pakistani]. His new move to the United States was challenging enough as he had left everything that was familiar to him in India. The added shock value of the treatment he received once he arrived added to his feelings of insecurity and powerlessness. Years later as he narrated his first few months of living in America to me, he shared that these experiences caused him to lose many sleepless nights. He had felt humiliated by the personal attacks on him and years later still carried these feelings with him.

For some Sikh men, the aftermath of $9 / 11$ has impacted their relationships. Dev Singh, who was 34-years old at the time of the attack, discussed the relational strain between himself and several of his White non-Sikh friends. Their friendships began prior to $9 / 11$, however shifted soon after. Dev Singh felt that "suspicion" and "mistrust" soon began to dictate their relationship after 9/11. Even though this group of friends had known each other for several years, an "us and them" attitude began to surface. Some time after 9/11, one of Dev Singh's friends suggested he cut his hair and remove his turban as an attempt to ward off unwanted attention, which only strained their friendship further. Dev Singh has experienced several instances where suspicion has gotten in the way of forming deeper more meaningful relationships.

\footnotetext{
${ }^{2}$ Most male Sikhs have Singh (lion) as their middle name or last name. The men reflected in this article all carry the name Singh. In an effort to promote equality and brotherhood, the tenth Guru gave this name to all Sikh men who identified as Sikh.
} 


\section{What I Know}

The greatest lesson I have learned from the Sikh men who have shared their experiences with me is that witnessing someone's story is essential for healing to occur. The dominant stories that have surrounded these men are of suspicion and mistrust. These leading discourses have allowed little room for stories that truly represent them. For the most part, these men have not had the opportunity to share the injustices that have taken place in their lives. Taking the time to explore all of the sociopolitical factors that may be influencing a Sikh man can be incredibly beneficial. Asking questions about self in relation to the world he lives in is critical. Time and time again, Sikh men ask me to tell their story in some form. They want the world to know the injustices that they suffer. They want others to know of the injuries they bear, they want their feelings of devaluation and the intangible losses they have had, witnessed. Further, they hope that telling their story will move someone to step in the next time a turbaned Sikh man is assaulted or degraded.

Another lesson I have learned involves being an advocate for social justice. This tenet holds incredible power with the followers of Sikhism. Despite the pain associated with 9/11 many Sikh men have actively engaged in community initiatives that aim to dismantle the hate that has impacted their lives. In my work with these men, I have often encouraged their journey of living a just life in an effort to increase healing and empowerment. These men have taken great strides to be a transformative force not only in their own lives, but also in the lives of others. Working within a framework of solidarity, equality, and one that values human rights is critical when working with the Sikh community or any community.

\section{A Commitment to Systemic Change within our Profession}

While working from a social justice perspective requires psychotherapists to move clients towards living a more just life, it also requires that we question the field in its unjust practices. With the tragedies surrounding Trayvon Martin, Sikh men, and other members of disenfranchised groups, injustices in North America are far from over. Racism is an established practice that is reflected in every part of society. The sociopolitical context in which psychotherapy is rooted, reflects society's position on privileging Whiteness over other. Psychological and relational well-being is still primarily based on White descriptions of what it means to be healthy. Literature on race and ethnicity in psychotherapy has expanded over time, yet this knowledge in mainstream training is still considered an exclusive topic of interest (Hardy \& McGoldrick, 2008).

Although efforts are being made to recognize and understand Sikhs as a people in the context of psychological health, researchers and clinicians engaged in this endeavor only a few. Further, these people are seen as pursuing work that deviates from what is valued. Working from a position of social justice requires that we not only make greater space for conversations that reflect the lives of Sikhs, but also make space for research, theory and practice that stems from the wisdom that Sikhs have on their psychological well-being as part of mainstream knowledge that is accessible. This systems level change requires that those who contribute to the advancement of knowledge commit to restructuring their work for different and inclusive conversations, research, theories, and practices. (Hardy \& McGoldrick, 2008). Acknowledging Sikhs as equal contributors to North American life and abolishing the notion that North America is homogenous is essential in shifting the racism that has seeped into our profession. 
Developing respect and an appreciation for Sikhs and others requires that we as professionals commit to a process of critical introspection (Hardy \& Laszloffy, 2002). A process of selfexploration is necessary in order to understand how our values, beliefs, and practices have been shaped by the dominant sociopolitical context of racism.

\section{Closing Thoughts}

While Sikhs form the fifth largest religion in the world, and have been living in North America since the early $19^{\text {th }}$ century, there remains a dearth of knowledge on this minority group in the broader mental health field. A sentiment shared among the Sikh men I have worked with is that psychotherapists are generally unaware of the Sikh community. In my own professional circles, it is rare for another psychotherapist to know what I am referring to when I identify as a Sikh. It is unacceptable to not know that Sikhs are a part of North American society. As psychotherapists and researchers we must take the initiative to know something about the people who may walk through our doors. A failure to do so can easily perpetuate the "othering" that so often happens for turbaned Sikh men. Further, our work involves building connections and shortening distances between others. Trayvon Martin was "othered" the night he lost his life. His death has propelled me to take action in solidarity with all those who are seen as suspicious because of their skin color, hoodie, turban, hijab, wavecap, or kufi. So I start here by sharing the voices of all those who have gone unnoticed. My hope is that their voices will become centralized. That they will be treated with dignity and respect and that there will never be a precious life lost like Trayvon Martin's ever again.

\section{Post-Script}

On August 5, 2012, after the submission of this manuscript, another hate crime took place. A White supremacist shot and killed six Sikhs and wounded several others at the Gurudwara in Oak Creek, Wisconsin. Since then, Sikhs around the country have received an overwhelming amount of support and prayers. Strangers and non-Sikhs, with messages of empathy and compassion have approached the Sikh community. While many have condemned the violence, sadly others have justified the shootings by their xenophobic discourse. Sikhs live at the crossroads of acceptance, love, kindness, and hate. Despite the horrific nature of the crime, the attack on the Sikh community is not entirely surprising. Yet the overwhelming response has been inspiring and uplifting. Sikh Americans have taken it upon themselves to respond with a unified message of peace, to challenge undertones of racism, and to provide collective healing by standing in solidarity with other communities, to all those who have suffered.

\section{Contact information:}

Kiran S. K. Arora

Assistant Professor in the Family Therapy Program

University of Massachusetts Boston

Email: Kiran.Arora@umb.edu 


\section{References}

Ahluwalia, M.K. \& Pellettiere, L. (2010). Sikh men post-9/11: Misidentification, discrimination, and coping. Asian American Journal of Psychology, 1(4), pp. 303-314. doi $10.1037 / \mathrm{a} 0022156$

Arora, K.S.K. (2009). Breaking the silence: The impact of political violence in Sikh diaspora. (Doctoral dissertation). Retrieved from PsycINFO. (AAI3381558).

Gohil, N.S. \& Sidhu, D.S. (2008). The Sikh Turban: Post-9/11 Challenges to this article of faith. Rutgers Journal of Law and Religion, 9, 10-72.

Hardy, K.V., \& Laszloffy, T.A. (2002). Couple therapy using a multicultural perspective. In A.S. Gurman \& N.S. Jacobson (Eds.), Clinical handbook of couple therapy ( $3^{\text {rd }}$ ed.) (pp. 569596). New York: Guilford Press.

Hardy, K.V., \& McGoldrick, M. (2008). Re-visioning training. In M. McGoldrick \& K.V. Hardy (Eds.). Re-visioning family therapy ( ${ }^{\text {nd }}$ ed.) (pp. 442-460). New York: Guilford Press.

United Sikhs. (n.d.). About Sikhs. Retrieved from http://www.unitedsikhs.org 